\title{
Normetanephrine Measurement
}

National Cancer Institute

\section{Source}

National Cancer Institute. Normetanephrine Measurement. NCI Thesaurus. Code

C122138.

The determination of the amount of normetanephrine present in a sample. 